\title{
Fault Tolerant Control Strategy Based on Model Predictive Control and Unscented Kalman Filter for Permanent Magnet Synchronous Motor*
}

\author{
Ahmed Aboelhassan \\ Key Laboratory of More Electric Aircraft \\ Technology of Zhejiang Province, \\ University of Nottingham, Ningbo, China. \\ Ahmed.Aboelhassan@nottingham.edu.cn
}

\author{
Waseem El Sayed \\ Electrical Engineering, Mathematics \& \\ Computer Science (EEMCS), \\ University of Twente, Enschede, Netherlands. \\ w.wafiksaadelsayed@utwente.nl
}

\author{
Ahmed Hebala \\ PEMC Group, University of Nottingham, \\ Nottingham, United Kingdom. \\ Ahmed.hebala@nottingham.ac.uk
}

\author{
Michael Galea \\ Key Laboratory of More Electric Aircraft \\ Technology of Zhejiang Province, University of \\ Nottingham, Ningbo, China. \\ Michael.Galea@nottingham.edu.cn
}

\author{
Serhiy Bozhko \\ Key Laboratory of More Electric Aircraft \\ Technology of Zhejiang Province, University \\ of Nottingham, Ningbo, China. \\ Serhiy.Bozhko@nottingham.edu.cn
}

\begin{abstract}
Permanent Magnet Synchronous Motors (PMSMs) are now extensively used in many critical applications. There is an increasing need for the motor and control system to have fault tolerant capabilities. This paper presents a fault tolerant control strategy to operate the PMSM during inter-turn fault conditions. The proposed technique combines the Model Predictive Control (MPC) for the speed and current control loops, and an almost error-free Unscented Kalman Filter (UKF) to estimate the PMSM inter-turn fault ratio. The PMSM statespace model for healthy and faulty conditions will be presented. Also, the equations and the remedial action of the MPC and UKF are provided in detail. The proposed algorithm is applied to PMSM model as a case study with a range of simulation analysis and discussion of results.
\end{abstract}

Keywords - fault tolerant, fault diagnosis, Model predictive control, unscented Kalman filter, PMSM.

\section{INTRODUCTION}

Permanent Magnet Synchronous Motors (PMSMs) have been widely utilized in many crucial and critical applications such as propulsion for the railway, electrical trains, electrical vehicles, and recently electrical aircraft [1]-[4] as well as other safety critical application in chemical or petrochemical industries [5]. PMSMs have the privilege of being one of the highest efficiency motors, and currently have a very wide selection of speed-torque profiles as well as competing with very high torque and power density designs [6]-[9].

The PMSM may be exposed to fault's existence during the operation, these faults could be mechanical, electrical, or magnetic [9], [10]. In this context, an extensive range of studies was conducted for fault diagnosis of PMSM, especially for the safety critical applications. The utilized fault diagnosis techniques for PMSM faults can be divided into three main types: signal-based, knowledge-based, and model-based. The signal based techniques such as Wavelet transform, Hilbert-Huang transform, and motor control signature analysis were used for PMSM fault diagnosis in

* This work was supported by the Natural Science Foundation of China, through the project with code 51850410515 .
[11],[12], and [13] respectively. However, these techniques take a long time in analysing the measured data which may not be suitable for all types of faults. Also, Artificial Intelligence (AI) techniques are being used such as knowledge-based fault diagnosis techniques for PMSM faults, for example, Neural Networks [14], fuzzy logic [15], and particle swarm optimization [16]. However, the AI techniques require a set of data logging measurements for the machine in case of fault which sometimes not available in all machine cases. On the other hand, model-based techniques such as the recursive least square method [17] or Kalman filter techniques, i.e. extended Kalman filter and Unscented Kalman Filters (UKF) [18]-[20] for PMSM fault diagnosis. However, not all the PMSM faults can be addressed utilizing the model-based techniques due to the unavailability of the fault mathematical model.

Fault tolerant can be considered from the early stages of the design of the PMSM. Therefore, it should have the ability to operate even with some possible faults mainly to the winding, at derated values, or the same values [21]. Fault tolerant motors will tend to have lower efficiency and bigger volume to incorporate with these requirements [22]. On the other hand, the fault tolerant strategy could be achieved through a modified or enhanced inverter design, or advanced control and parameter estimation control loops [23]. The proper fault tolerant control system should identify the fault type correctly, then perform the remedial action through the controller.

Model Predictive Control (MPC) has been successfully applied for many applications including electrical machines [24], [25]. It provides a faster response than the conventional PID controller especially in the presence of the cascaded PMSM control loops at field oriented control strategy [26]. Recently, it has been used as a fault tolerant technique to provide a remedial control action under fault conditions [27]. In [28] and [29], MPC based on finite control set strategy has been used as a pre and post fault controller for open circuit fault of multi-phase PMSMs. 
So, a fault tolerant control strategy based on the MPC controller employing UKF for inter-turn fault detection is proposed. The rest of the paper is organized as follows: In section II, the PMSM model in both the healthy and faulty state is given in full detail, while the UKF technique is introduced in section III. MPC implementation and the fault tolerant action are illustrated in Section IV. The results and analysis of the proposed algorithm applied to PMSM are presented in Section V, followed by the conclusion in Section VI.

\section{PMSM MODEL}

The mathematical state space model of the PMSM is essential for both the UKF estimator and the MPC controller. The mathematical model of the PMSM can be divided into two parts: the healthy state model and the faulty state model [17], [26]. It will be detailed in the following sub-section II. $a$, and II. b.

\section{a) Healthy state model}

The PMSM model is represented in the dq-frame as:

$$
\begin{gathered}
\mathbf{v}_{\mathrm{sd}}=R_{s} \mathbf{i}_{s d}+L_{q} p\left(\mathbf{i}_{s d}\right)-\omega_{e} L_{q} \mathbf{i}_{s q} \\
\mathbf{v}_{\mathrm{sq}}=R_{s} \mathbf{i}_{s q}+L_{q} p\left(\mathbf{i}_{s q}\right)+\omega_{e} \lambda-\omega_{e} L_{d} \mathbf{i}_{s d} \\
p \omega_{e}=\frac{p p}{j}\left(T_{e}-\frac{B_{f}}{p p} \omega_{e}-T_{l}\right) \\
T_{e}=\frac{3}{2} p p\left(\lambda \mathbf{i}_{s q}-\left(L_{q}-L_{q}\right) \mathbf{i}_{s q} \mathbf{i}_{s d}\right)
\end{gathered}
$$

where $\mathbf{v}_{\mathrm{sd}}, \mathbf{v}_{\mathrm{sq}}, \mathbf{i}_{s d}, \mathbf{i}_{s q}, L_{d}$ and $L_{q}$ are the stator's voltage, current, and inductance respectively for dq-frame. $R_{S}$ is the stator resistance, $\lambda$ is the flux linkage of the machine, $\omega_{e}, p$ and $p p$ are electrical angular velocity, the machine poles and pole pairs respectively. $j, B_{f}$ and $T_{l}$ represent the machine inertia, friction constant, and load torque respectively, and the $T_{e}$ is the electrical torque. As the PMSM model is nonlinear, the Taylor expansion is used to develop the linearized equations for the model around a definite operating point given by (5) and (6):

$$
\begin{gathered}
\mathbf{i}_{s d} \omega_{e}=\omega_{e 0} \mathbf{i}_{s d 0}+\mathbf{i}_{s d 0}\left(\omega_{e}-\omega_{e 0}\right)+\omega_{e 0}\left(\mathbf{i}_{s d}-\mathbf{i}_{s d 0}\right) \\
\mathbf{i}_{s q} \omega_{e}=\omega_{e 0} \mathbf{i}_{s q 0}+\mathbf{i}_{s q 0}\left(\omega_{e}-\omega_{e 0}\right)+\omega_{e 0}\left(\mathbf{i}_{s q}-\mathbf{i}_{s q 0}\right)
\end{gathered}
$$

where $\omega_{e 0}, \mathbf{i}_{s d 0}$ and $\mathbf{i}_{s q 0}$ are the linearized model operating points.

\section{b) Faulty state model}

The fault is presented by the added impedance $\mathbf{z}_{\mathbf{s} / \mathbf{c}}$ to the machine equation which causes the increase in the consumed current from the machine. In this case, the total current of the machine can be expressed as:

$$
\mathbf{i}_{\mathrm{s} d q}^{\prime}=\mathbf{i}_{s d q}+\mathbf{i}_{\mathrm{s} / \mathrm{c}_{d q}}^{\prime}=\mathbf{i}_{s d q}+\mathbf{z}_{\mathrm{s} / \mathrm{c}_{d q}^{-1}}^{-1} \mathbf{v}_{\mathrm{s}_{d q}}
$$

where

$$
\begin{gathered}
\mathbf{z}_{\mathbf{s} / \mathbf{c}_{d q}^{-1}}=\sum_{k=1}^{3} \frac{2 n_{S / C k}}{\left(3-2 n_{S / C k}\right) R_{s}} \mathrm{P}(\theta)^{\mathrm{T}} \mathrm{Q}\left(\theta_{\mathrm{s} / c}\right) \mathrm{P}(\theta)^{\mathrm{T}} \\
\mathrm{P}(\theta)_{2 \times 2}=\left[\begin{array}{cc}
\cos \theta & -\sin \theta \\
\sin \theta & \cos \theta
\end{array}\right] \\
\mathrm{Q}\left(\theta_{\mathrm{S} / c}\right)_{2 \times 2}=\left[\begin{array}{cc}
\cos ^{2} \theta_{\mathrm{S} / \mathrm{C}} & \sin \theta_{\mathrm{S} / \mathrm{C}} \cos \theta_{\mathrm{S} / \mathrm{C}} \\
\sin \theta_{\mathrm{S} / \mathrm{C}} \cos \theta_{\mathrm{S} / \mathrm{C}} & \sin ^{2} \theta_{\mathrm{S} / \mathrm{C}}
\end{array}\right]
\end{gathered}
$$

$\mathbf{i}_{\mathrm{s} d q}^{\prime}$ is the total consumed current from the machine in case of the fault, $P(\theta)_{2 \times 2}$ is the dq-transformation matrix, $\mathrm{Q}\left(\theta_{\mathrm{s} / c \mathrm{k}}\right)_{2 \times 2}$ is the localization matrix, $n_{S / C k}$ represents the short circuit turns ratio of the fault at a definite phase $k$ and $\theta_{\mathrm{s} / c}$ is the phase location of the fault at $0, \frac{2 \pi}{3}$ or $\frac{4 \pi}{3}$.

\section{c) The General state-space model}

The PMSM equations could be represented in the state space model as:

$$
\left\{\begin{array}{c}
\dot{\mathbf{x}}_{\mathbf{c}}(\mathbf{t})=\mathrm{A}_{\mathrm{c}} \cdot \mathbf{x}_{\mathbf{c}}(\mathbf{t})+\mathrm{B}_{\mathrm{c}} \cdot \mathbf{u}_{\mathbf{c}}(\mathbf{t})+\boldsymbol{\delta}_{\mathbf{c}} \\
\mathbf{y}_{\mathbf{c}}(\mathbf{t})=\mathrm{C}_{\mathrm{c}} \cdot \mathbf{x}_{\mathbf{c}}(\mathbf{t})+\mathrm{D}_{\mathrm{c}} \cdot \mathbf{u}_{\mathbf{c}}(\mathbf{t})
\end{array}\right.
$$

where

$$
\begin{aligned}
& \mathrm{x}_{\mathrm{c}}(\mathrm{t})^{\mathrm{T}}=\left[\begin{array}{lll}
\mathbf{i}_{s d} & \mathbf{i}_{s q} & \omega_{\mathrm{e}}
\end{array}\right] \\
& \mathbf{u}_{\mathbf{u}}(\mathbf{t})^{\mathbf{T}}=\left[\begin{array}{ll}
\mathbf{v}_{\mathrm{sd}} & \mathbf{v}_{\mathrm{sq}}
\end{array}\right] \\
& \mathbf{y}_{\mathbf{c}}(\mathbf{t})^{\mathbf{T}}=\left[\begin{array}{lll}
\mathbf{i}_{s d}^{\prime} & \mathbf{i}_{s q}^{\prime} & \omega_{\mathrm{e}}
\end{array}\right] \\
& \mathrm{A}_{\mathrm{c}}=\left[\begin{array}{ccc}
-\frac{R_{s}}{L_{d}} & \omega_{e 0} & \mathbf{i}_{s q 0} \\
-\omega_{e 0} & -\frac{R_{S}}{L_{q}} & -\left(\mathbf{i}_{s d 0}+\frac{\lambda}{L_{q}}\right) \\
0 & \frac{3 P^{2} \lambda}{2 J} & -\frac{B_{f}}{J}
\end{array}\right] \\
& \mathrm{B}_{\mathrm{c}}=\left[\begin{array}{cc}
1 / L_{d} & 0 \\
0 & 1 / L_{q} \\
0 & 0
\end{array}\right] \\
& C_{c}=\left[\begin{array}{lll}
1 & 0 & 0 \\
0 & 1 & 0 \\
0 & 0 & 1
\end{array}\right] \\
& \boldsymbol{\delta}_{\mathbf{c}}=\left[\begin{array}{c}
-\omega_{e 0} \mathbf{i}_{s q 0} \\
\omega_{e 0} \mathbf{i}_{s d 0} \\
-\frac{p p . T_{l}}{J}
\end{array}\right] \\
& \mathrm{D}_{\mathrm{c}}=\left[\begin{array}{c}
\mathrm{D}_{1} \\
0
\end{array}\right] \\
& \mathrm{D}_{12 \times 2}=-\sum_{k=1}^{3} \frac{2 n_{\frac{s}{c} k}}{\left(3-2 n_{\bar{c} k}\right) R_{s}} \mathrm{P}(\theta)^{\mathrm{T}} \mathrm{Q}\left(\theta_{\mathrm{s} / c \mathrm{k}}\right) \mathrm{P}(\theta)
\end{aligned}
$$

where $\mathbf{x}_{\mathbf{c}}(\mathbf{t}), \mathbf{u}_{\mathbf{c}}(\mathbf{t})$ and $\mathbf{y}_{\mathbf{c}}(\mathbf{t})$ represent the state, input, and output vectors. $A_{c}, B_{c}, C_{c}$ and $D_{c}$ represent state, input, output, and feed forward matrices. 


\section{The Proposed FAUlt Diagnosis AlgORITHM}

The proposed technique is one of the model-based techniques to gain the merits of the machine state-space model presence in both, healthy and faulty conditions. UKF is one of the recursive techniques based on the state space model. It can estimate the values of the unmeasurable parameters inside the nonlinear systems.

\section{a) Discretization and Extending of the states}

The first step in the UKF procedures is to extend the states with the unknown parameters such as:

$$
\begin{aligned}
& \tilde{\mathbf{x}}_{k}=\left[\begin{array}{c}
\mathbf{x}_{\mathbf{c}}(\mathbf{t}) \\
\boldsymbol{\gamma}(\mathbf{t})
\end{array}\right]= \\
& {\left[\begin{array}{llllll}
I_{s d}^{\prime} & I_{s q}^{\prime} & \omega_{e} & n_{A s / c} & n_{B s / c} & n_{B s / c}
\end{array}\right]^{T}}
\end{aligned}
$$

where $\tilde{\mathbf{x}}_{k}$ represents the total estimated states, $\boldsymbol{\gamma}(\mathbf{t})$ is the additional estimated parameters to the original states, $n_{A s / c}, n_{B s / c}$ and $n_{C s / c}$. The discretizing using Taylor first order equation can be expressed as:

where

$$
\left\{\begin{array}{c}
\tilde{\mathbf{x}}_{k+1}=\mathrm{F}_{k} \tilde{\mathbf{x}}_{k}+\mathrm{B}_{k} \mathbf{u}_{k}+\mathbf{w}_{k} \\
\tilde{\mathbf{y}}_{k}=\mathrm{H}_{k} \tilde{\mathbf{x}}_{k}+\mathrm{D}_{k} \mathbf{u}_{k}+\mathbf{v}_{k}
\end{array}\right.
$$

$$
\begin{gathered}
\mathrm{F}_{\mathrm{k}}=\left[\begin{array}{cc}
1+T_{s} \cdot \mathrm{A}_{c} & 0 \\
0 & \mathrm{I}_{3 \times 3}
\end{array}\right] \\
\mathrm{B}_{k}=\left[\begin{array}{c}
T_{s} \cdot \mathrm{B}_{c} \\
0_{3 \times 3}
\end{array}\right] \\
\mathrm{H}_{k}=\mathrm{C}_{c} \\
\mathrm{D}_{k}=\mathrm{D}_{c}
\end{gathered}
$$

\section{b) UKF Algorithm}

The UKF calculates the sigma points of the posterior estimated states and works recursively to decrease the error between the current states and the posterior ones [30]. This approach will provide more accuracy for the estimated states than other Kalman filter techniques [31]. The equations of the UKF can be divided into three groups: the first group is the initialization and calculation of sigma points, the second group is the time update process, and the third group is the measurement update process. The initialization process is the set of initial values for the estimated states $\hat{\mathbf{x}}_{0}^{a}$ and the covariance matrix $\mathrm{P}_{0}^{\mathrm{a}}$, assuming the estimated states $\tilde{\mathbf{x}}_{k}$ has the mean of $\widehat{\mathrm{X}}_{k-1}^{a}$ and the covariance matrix of $\mathrm{P}_{k-1}^{a}$. Also, a matrix of $2 L+1$ sigma vector $\mathrm{X}_{k-1}^{a}$ could be formed, where $L$ is the length of the estimated states vector and $\gamma$ is a weighing factor equal to $\alpha^{2}((L+k)-L)$. $\alpha$ could be tuned from $10^{-4}$ to 1 and $k$ usually is set to zero.

The time update equations include the calculation of the covariance matrix $\mathrm{P}_{k}$ based on (14), $W_{i}^{m}$ and $W_{i}^{C}$ are weighting factors and they are equal to $1 / 2(L+\gamma)$. Finally, the measurement update equations will include the Kalman gain $K_{k}$ for the correction of the next state estimation $\hat{\mathbf{x}}_{k}$ and covariance matrix $\mathrm{P}_{k}$. Fig. 1 shows the UKF algorithm flowchart, including equations of the three groups.

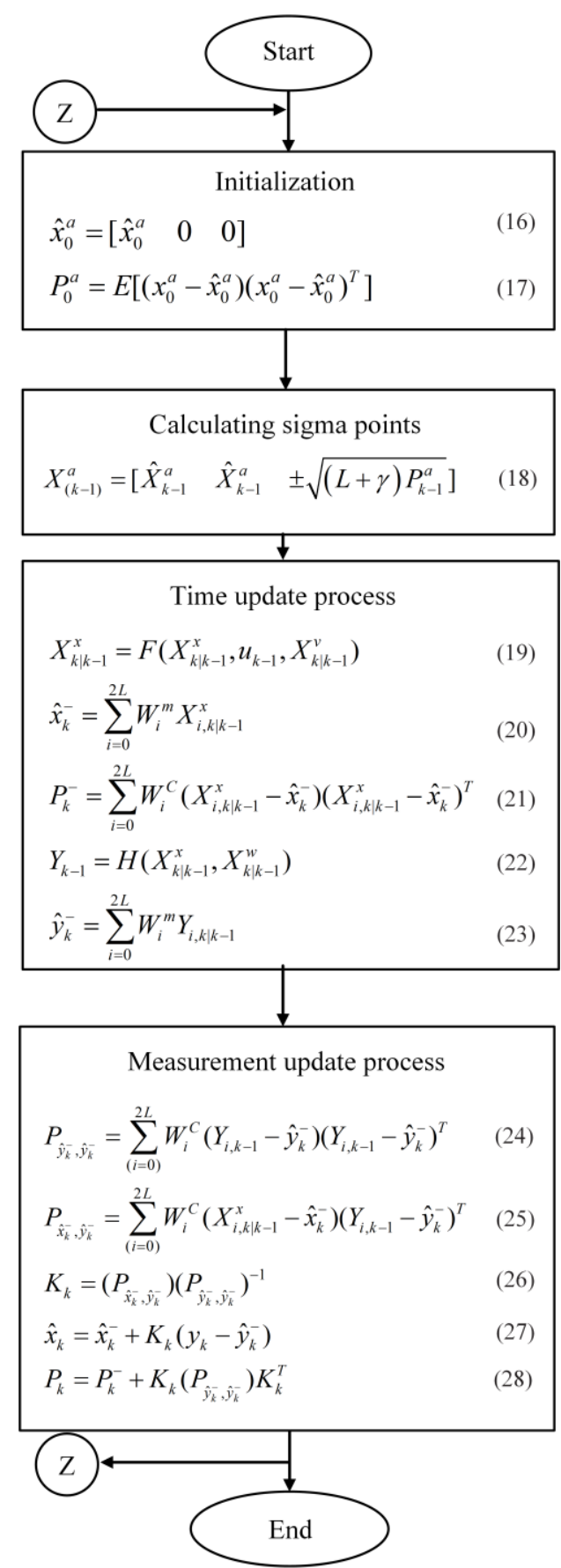

Fig. 1. The UKF algorithm flowchart.

\section{The Proposed FAUlt TOLERANT AlgOrithM}

The fault tolerant scenario is developed based on the MPC controller to achieve a faster behaviour under faulty conditions than classical control techniques. The MPC controller and its equations will be illustrated followed by the remedial action of the control system in case of the inter-turn fault.

\section{a) The model predictive control}

MPC has been developed as a successful controller to improve the system's response and robustness. The MPC cost function could be illustrated by [32]: 


$$
\boldsymbol{j}=\sum_{k=1}^{n_{y}} \mathbf{e}^{\mathrm{T}}(k) \mathrm{Q}(k) \mathbf{e}(k)+\sum_{k=0}^{n_{u}-1} \mathbf{u}^{\mathrm{T}}(k) \mathrm{R}(k) \mathbf{u}(k)
$$

subject to the discretised PMSM model in (14), where $\mathbf{e}(k)_{3 * 1}=\mathbf{y}(k)_{3 * 1}-\mathbf{r}(k)_{3 * 1}$ is the system error, $\mathbf{y}(k)_{3 * 1}$ is the output, $\mathbf{r}(k)_{3 * 1}$ is the reference, $\mathbf{u}(k)_{2 * 1}$ is the controlled input, $\mathrm{Q}(k)_{3 * 3}$ and $\mathrm{R}(k)_{2 * 2}$ are weighting matrices, $n_{y}$ is the prediction horizon and $n_{u}$ is the control horizon. The model will be employed recursively through $n_{y}$ such as:

$$
\begin{gathered}
\widehat{\mathbf{x}}(k+1)=\mathrm{P}_{\mathrm{x}} \mathbf{x}(k)+\mathrm{H}_{\mathrm{x}} \widehat{\mathbf{u}}(k) \\
\hat{\mathbf{y}}(k+1)=\mathrm{P} \mathbf{x}(k)+\mathrm{H} \widehat{\mathbf{u}}(k)
\end{gathered}
$$

where

$$
\begin{aligned}
& \hat{\mathbf{x}}(k+1)=\left[\begin{array}{c}
\mathbf{x}(k+1) \\
\mathbf{x}(k+2) \\
\mathbf{x}(k+3) \\
\vdots \\
\mathbf{x}\left(k+n_{y}\right)
\end{array}\right] \\
& \mathrm{P}_{\mathrm{x}}=\left[\begin{array}{c}
\mathrm{A} \\
\mathrm{A}^{2} \\
\mathrm{~A}^{3} \\
\vdots \\
\mathrm{A}^{n_{y}}
\end{array}\right] \\
& \mathrm{H}_{\mathrm{x}}=\left[\begin{array}{cccc}
\mathrm{B} & 0 & 0 & \ldots \\
\mathrm{AB} & \mathrm{B} & 0 & \ldots \\
\mathrm{A}^{2} \mathrm{~B} & \mathrm{AB} & \mathrm{B} & \ldots \\
\vdots & \vdots & \vdots & \vdots \\
\mathrm{A}^{n_{y}-1} \mathrm{~B} & \mathrm{~A}^{n_{y}-2} \mathrm{~B} & \mathrm{~A}^{n_{y}-3} \mathrm{~B} & \ldots
\end{array}\right] \\
& \widehat{\mathbf{u}}(k)=\left[\begin{array}{c}
\mathbf{u}(k) \\
\mathbf{u}(k+1) \\
\mathbf{u}(k+2) \\
\vdots \\
\mathbf{u}\left(k+n_{y}-1\right)
\end{array}\right] \\
& \hat{\mathbf{y}}(k+1)=\left[\begin{array}{c}
\mathbf{y}(k+1) \\
\mathbf{y}(k+2) \\
\mathbf{y}(k+3) \\
\vdots \\
\mathbf{y}\left(k+n_{y}\right)
\end{array}\right] \\
& \mathrm{P}=\left[\begin{array}{c}
\mathrm{CA} \\
\mathrm{CA}^{2} \\
\mathrm{CA}^{3} \\
\vdots \\
\mathrm{CA}^{n_{y}}
\end{array}\right] \\
& \mathrm{H}=\left[\begin{array}{cccc}
\mathrm{CB} & 0 & 0 & \ldots \\
\mathrm{CAB} & \mathrm{CB} & 0 & \ldots \\
\mathrm{CA}^{2} \mathrm{~B} & \mathrm{CAB} & \mathrm{CB} & \ldots \\
\vdots & \vdots & \vdots & \vdots \\
\mathrm{CA}^{n_{y}-1} \mathrm{~B} & \mathrm{CA}^{n_{y}-2} \mathrm{~B} & \mathrm{CA}^{n_{y}-3} \mathrm{~B} & \ldots
\end{array}\right]
\end{aligned}
$$

$\hat{\mathbf{x}}(k+1)_{\left(3 * n_{y}\right) * 1}$ is the predicted states, $\hat{\mathbf{y}}(k+1)_{\left(3 * n_{y}\right) * 1}$ is the output, $\widehat{\mathbf{u}}(k)_{\left(2 * n_{y}\right) * 1}$ is the controlled input and $\mathrm{P}_{x\left(3 * n_{y}\right) * 3}$ , $\mathrm{H}_{x\left(3 * n_{y}\right) *\left(2 * n_{y}\right)}, \mathrm{P}_{\left(3 * n_{y}\right) * 3}, \mathrm{H}_{\left(3 * n_{y}\right) *\left(2 * n_{y}\right)}$ are the system parameters. The solution of (29) considering $\mathbf{u}(k)$ is [33]:

$$
\begin{gathered}
\mathbf{u}(k)_{\mathbf{M P C}}=\mathrm{L}\left[\left(\mathrm{H}^{\mathrm{T}} \widehat{\mathrm{Q}}(k) \mathrm{H}+\right.\right. \\
\left.\left.\mathrm{H}^{\mathrm{T}} \widehat{\mathrm{Q}}^{\mathrm{T}}(k) \mathrm{H}+2 \widehat{\mathrm{R}}^{\mathrm{T}}(k)\right)^{-1} 2 \mathrm{H}^{\mathrm{T}} \widehat{\mathrm{Q}}^{\mathrm{T}}(k)(\widehat{\mathbf{r}}(k)-\mathrm{Px}(k))\right]
\end{gathered}
$$

where $\mathrm{L}_{2 *\left(2 * n_{y}\right)}=$ [I 0 ] with $\mathrm{I}_{2 * 2}$ is an identity matrix and $\mathrm{O}_{2^{*}\left(2^{*} \mathrm{ny}-2\right)}$ is a zero matrix, $\hat{\mathbf{r}}(k)_{\left(3 * n_{y}\right) * 1}$ is the reference, $\widehat{\mathrm{Q}}(k)_{\left(3 * n_{y}\right) *\left(3 * n_{y}\right)}$ and $\widehat{\mathrm{R}}(k)_{\left(2 * n_{u}-1\right) *\left(2 * n_{u}-1\right)}$ are weighting matrices. The system constraints have been handled through the implementation of a softening constraints method. The cost function will be [26]:

$$
\begin{gathered}
\boldsymbol{j}=\sum_{k=1}^{n_{y}} \mathbf{e}^{\mathrm{T}}(k) \mathrm{Q}(k) \mathbf{e}(k)+\sum_{k=0}^{n_{u}-1} \mathbf{u}^{\mathrm{T}}(k) \mathrm{R}(k) \mathbf{u}(k)+ \\
\sum_{k=0}^{n_{u}-1}(\mathbf{u}(k)-\overline{\mathbf{u}}(k))^{\mathrm{T}} \mathrm{S}(k)(\mathbf{u}(k)-\overline{\mathbf{u}}(k))
\end{gathered}
$$

where $\overline{\mathbf{u}}(k)_{2 * 1}$ is the controlled input constraint and its value is $\left[\begin{array}{ll}V_{d c} / 2 & -V_{d c} / 2\end{array}\right]^{T} \cdot \mathrm{S}(k)_{2 * 2}$ is the weighting matrix. The solution of (34) considering $\mathbf{u}(k)$ will be:

$$
\begin{gathered}
\mathbf{u}(k)_{\mathrm{MPC}}=\mathrm{L}\left[\left(\mathrm{H}^{\mathrm{T}} \widehat{\mathrm{Q}}(k) \mathrm{H}+\mathrm{H}^{\mathrm{T}} \widehat{\mathrm{Q}}^{\mathrm{T}}(k) \mathrm{H}+2 \widehat{\mathrm{R}}^{\mathrm{T}}(k)+\right.\right. \\
\left.\left.2 \widehat{\mathrm{S}}^{\mathrm{T}}(k)\right)^{-1}\left(2 \mathrm{H}^{\mathrm{T}} \widehat{\mathrm{Q}}^{\mathrm{T}}(k)(\hat{\mathbf{r}}(k)-\mathrm{P} \mathbf{x}(k))+2 \widehat{\mathrm{S}}^{\mathrm{T}}(k) \hat{\overline{\mathbf{u}}}(k)\right)\right]
\end{gathered}
$$

where $\widehat{\mathbf{u}}(k)_{\left(2 * n_{\mathcal{u}}-1\right) * 1}$ and $\widehat{\mathrm{S}}(k)_{\left(2 * n_{\mathcal{u}}-1\right) *\left(2 * n_{\mathcal{u}}-1\right)}$ are the constraints values and weighting matrix with length of $n_{u}-$ 1.

\section{b) Fault tolerant control action}

In order to make the machine operates in the presence of the stator inter-turn fault, the proposed strategy is to adjust the load torque which consequently decreases the phase current to an equivalent amount of the added value of the short circuit current without affecting the operating speed. This degradation in current will decrease the electrical stress to the winding insulation and prevents possible machine temperature increase. The proposed remedial action will give the operator enough time to prepare a redundant system or to proceed with any other backup scheme after the fault alarm has been triggered. As a result, the amount of torque degradation will depend on the value of the estimated short circuit turns ratio in any of the three phases. The relation between the load torque and the $n_{s / c}$ can be expressed as:

$$
\begin{gathered}
T_{l}^{*}=T_{l}-W n_{s / c A}-W n_{s / c B}-W n_{s / c C} \\
W=\frac{T_{l}}{n_{s / c}^{*}}-\frac{3 p p \lambda\left(I_{L_{\text {peak }}}^{\prime}-I_{L_{p e a k}}\right)}{2 n_{s / c}^{*}}
\end{gathered}
$$

where $T_{l}^{*}$ is the calculated reference load torque to the MPC controller after the existence of the fault, $n_{s / c}^{*}$ is the maximum applicable value of short circuit turns ratio that the machine could withstand, $I_{\text {Lpeak }}$ is the peak value of the instantaneous load current at the torque $T_{l}$ in the healthy state and $I_{L_{\text {peak }}}^{\prime}$ is the peak value of total instantaneous current consumed by the machine in case of short circuit turns ratio equal to $n_{s / c}^{*}$. Fig. 2 shows the block diagram of the FTC approach for the PMSM system. 


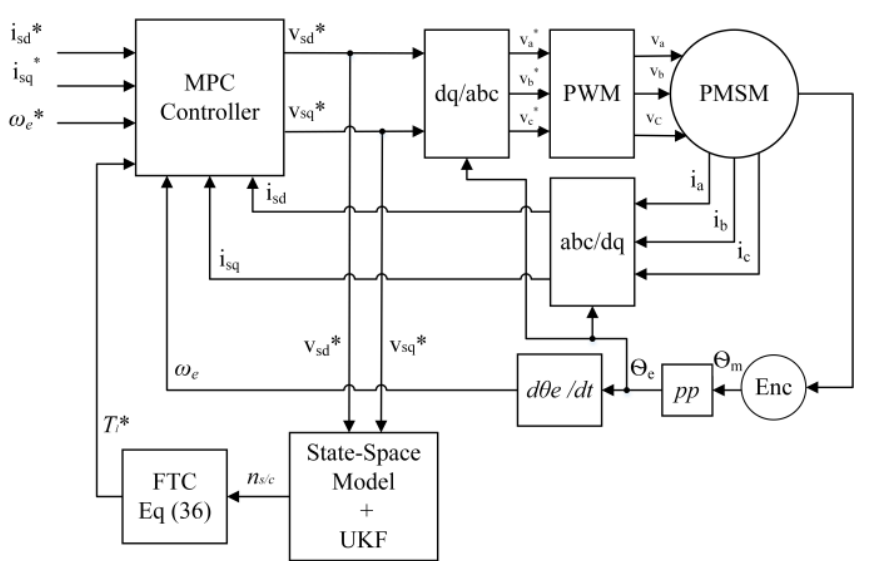

Fig. 2. The proposed FTC strategy for PMSM.

\section{RESULTS AND DISCUSSION}

The Simulation is developed using MATLAB Simulink workspace, the PMSM parameters are stated in TABLE I. The sampling time is selected to be $100 \mu \mathrm{Sec}$ to be suitable for the rated frequency and the time constant for the proposed machine.

\section{a) Fault detection results}

At $T=0.5 \mathrm{Sec}$, a stator inter-turn fault of $10 \%$ is simulated in phase A of the PMSM, the load current increased to reach a peak value of 13 A. As shown in Fig. 3, the fault causes a $31 \%$ increase in the value of the load current. In this case, the temperature of the machine is expected to increase, and high vibration will appear due to the unbalance phase currents. Also, the overcurrent protection will disconnect the motor due to the detected increase in the load current.

So, it is important to detect the presence of the fault before the protection device takes an isolation action. Fig. 4 shows the UKF estimation response of $n_{A S / C}$ in case of the fault. The estimation takes $0.02 \mathrm{Sec}$ ( 2 cycles of the rated angular velocity) to reach the steady state value. Also, the value of the estimated parameter is nearly identical to the reference value of the fault as illustrated in TABLE II. It shows the UKF estimation response of $n_{A S / C}$ at different values of $n_{A S / C}$ from $5 \%$ to $100 \%$. The estimation accuracy is significant in all fault cases. Besides, the fault estimation is tested for the other two phases and provides the same response.

TABLE I: PMSM NOMINAL PARAMETERS

\begin{tabular}{|c|c|}
\hline Machine Parameter & Value \\
\hline Power $(P)$ & $2300 \mathrm{~W}$ \\
\hline Current $(I s)$ & $9.5 \mathrm{~A}$ \\
\hline Voltage $(V s)$ & $220 \mathrm{~V}$ \\
\hline Frequency $(f)$ & $100 \mathrm{~Hz}$ \\
\hline Stator Resistance $\left(R_{s}\right)$ & $0.55 \Omega$ \\
\hline Stator Inductance $\left(L_{s}\right)$ & $2.225 \mathrm{mH}$ \\
\hline Torque $\left(T_{l}\right)$ & $6 \mathrm{Nm}$ \\
\hline Speed $(N s)$ & $1500 \mathrm{RPM}$ \\
\hline Pole Pairs $(p p)$ & 4 \\
\hline PM Flux $(\lambda)$ & $0.114 \mathrm{~Wb}$ \\
\hline
\end{tabular}

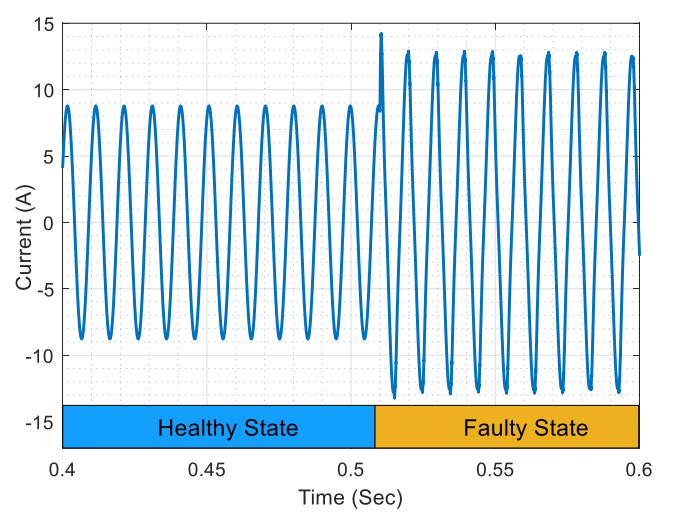

Fig. 3. The instantaneous values of the total consumed current $I_{L}^{\prime}$ at $n_{A S / C}=$ $10 \%$.

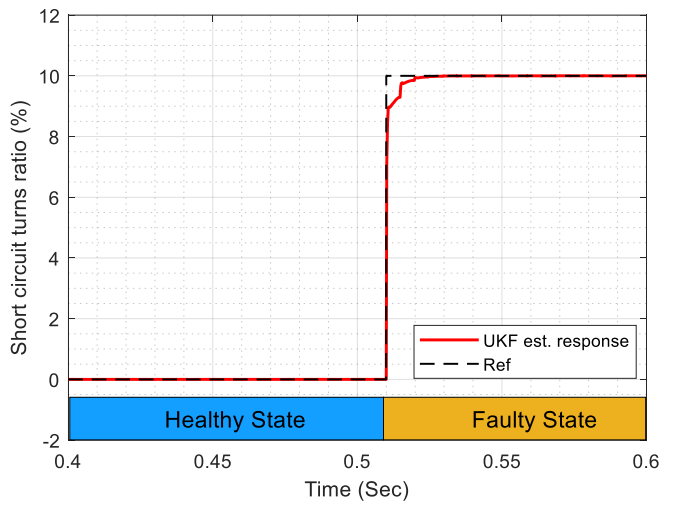

Fig. 4. Estimation response of $n_{A S / C}=10 \%$.

TABLE II: UKF ESTIMATION RESPONSE ANALYSIS

\begin{tabular}{|c|c|c|c|c|}
\hline $\begin{array}{c}\text { Operating } \\
\text { Points }\end{array}$ & $\begin{array}{c}\text { Total RMS } \\
\text { Current (A) }\end{array}$ & $\begin{array}{c}\text { Ref S/C } \\
\text { turns ratio } \\
(\%)\end{array}$ & $\begin{array}{c}\text { Estimated } \\
\text { S/C turns } \\
\text { ratio (\%) }\end{array}$ & $\begin{array}{c}\text { Error } \\
\mathbf{( \% )}\end{array}$ \\
\hline 1 & 7.30 & 5 & 5.01 & 0.200 \\
\hline 2 & 8.60 & 10 & 10.02 & 0.180 \\
\hline 3 & 10.6 & 15 & 15.00 & 0.020 \\
\hline 4 & 13.0 & 20 & 19.99 & 0.060 \\
\hline 5 & 15.5 & 25 & 24.99 & 0.024 \\
\hline 6 & 18.1 & 30 & 30.00 & 0.017 \\
\hline 7 & 20 & 35 & 35.00 & 0.009 \\
\hline 8 & 22 & 40 & 40.00 & 0.001 \\
\hline 9 & 24.8 & 45 & 45.00 & 0.001 \\
\hline
\end{tabular}

\section{b) Fault tolerant control Results}

To verify the fault tolerant topology, a scenario of stator interturn fault is simulated at phase A of $n_{s / c A}=2 \%$ and the fault starts to increase gradually by $2 \%$ every $0.5 \mathrm{Sec}$ at the rated load torque of $6 \mathrm{Nm}$ and 9 A load current peak value. The torque will start decreasing with the increase of the estimated $n_{s / c A}$ value based on (36) as shown in Fig. 5 and Fig. 6. On the other hand, the total consumed current of the machine remains relatively constant despite the increase of the fault percentage as shown in the RMS value of the total consumed current in Fig. 7. Besides, the speed is being maintained constant during all fault cases. However, a small tribulation appears in the speed when a higher fault severity is experienced as shown in Fig. 8. 


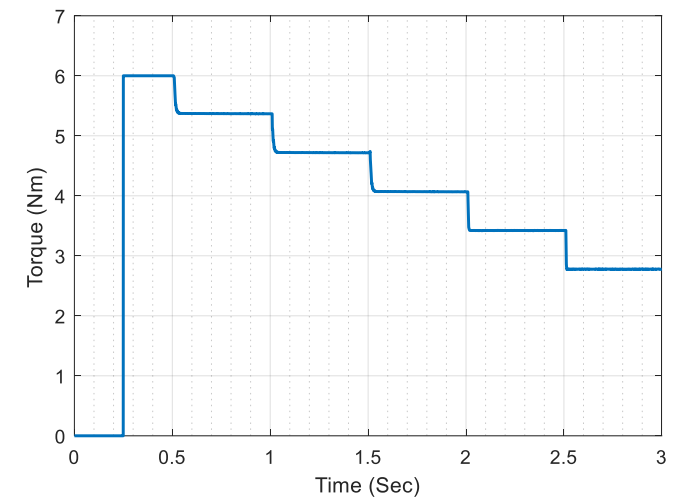

Fig. 5. Load torque when the fault increased by $2 \%$ every $0.5 \mathrm{Sec}$.

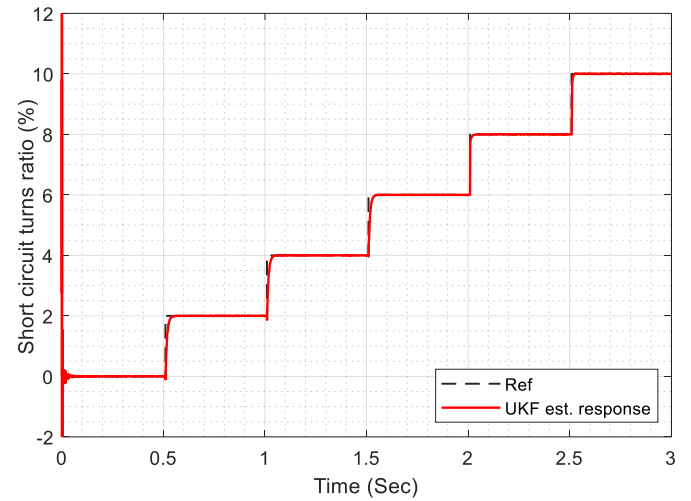

Fig. 6. The UKF $n_{s / c A}$ estimation at the gradual increase of the fault percentage.

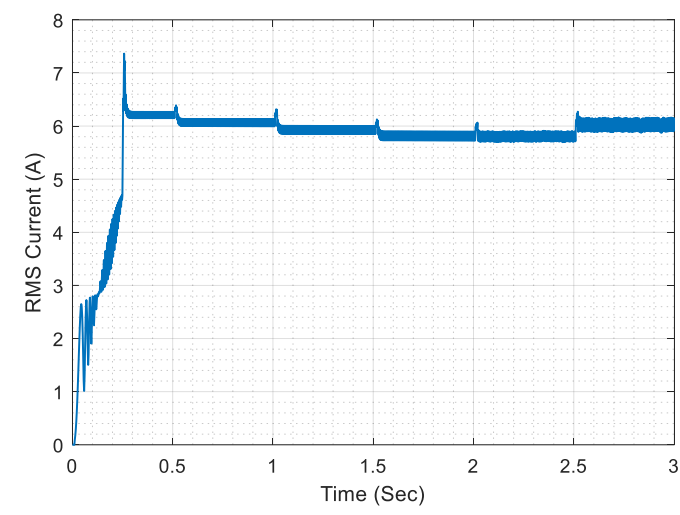

Fig. 7. The total machine RMS current after the FTC action.

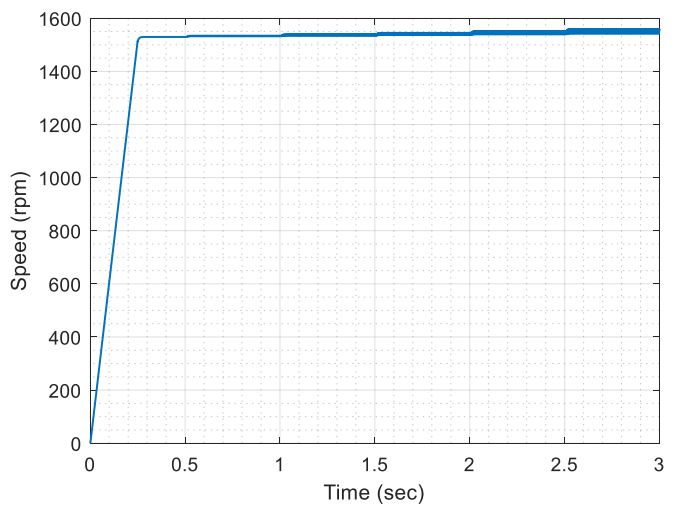

Fig. 8. Speed response at the fault case scenario.

\section{CONCLUSION}

The paper has presented a fault tolerant control approach for the inter-turn fault of PMSM. The PMSM healthy model is firstly introduced then the faulty model is presented as an integrated part of the estimating parameters procedure. The results proved the efficiency of the UKF in estimating the exact values of inter-turn fault ratios. Also, the MPC controller was applied successfully to have a faster response of the system to maintain the motor speed constant at inter-turn fault from $2 \%$ up to $10 \%$. This implementation keeps the phase current relatively unchanged and balanced despite the fault being localized in one phase. Although the motor torque is degraded, it is an acceptable procedure to keep the motor running at a reduced torque in the presence of the fault. The practical implementation of the proposed results will be considered in future work to extend the fault frame and fault tolerant strategies.

\section{REFERENCES}

[1] D. Lusignani, D. Barater, G. Franceschini, G. Buticchi, M. Galea, and C. Gerada, "A high-speed electric drive for the more electric engine," 2015 IEEE Energy Convers. Congr. Expo. ECCE 2015, pp. 4004-4011, 2015, doi: 10.1109/ECCE.2015.7310225.

[2] V. Madonna, P. Giangrande, and M. Galea, "Electrical Power Generation in Aircraft: review, challenges and opportunities," IEEE Trans. Transp. Electrif., vol. 7782, no. 665468, pp. 1-1, 2018, doi: 10.1109/TTE.2018.2834142.

[3] C. Gerada, M. Galea, and A. Kladas, "Electrical Machines for High Performance Aerospace Applications," in 2015 IEEE Workshop on Electrical Machines Design, Control and Diagnosis (WEMDCD), Torino, 2015, pp. 79-84, doi: 10.1109/WEMDCD.2015.7194513.

[4] A. M. Diab, S. Bozhko, M. Galea, and C. Gerada, "Stable and Robust Design of Active Disturbance-Rejection Current Controller for Permanent Magnet Machines in Transportation Systems," IEEE Trans. Transp. Electrif., vol. 6, no. 4, pp. 14211433, 2020, doi: 10.1109/TTE.2020.3001042.

[5] N. Yogal, C. Lehrmann, and M. Henke, "Magnetic loss measurement of surface-mounted permanent magnet synchronous machines used in explosive environments," J. Eng., vol. 2019, no. 17, pp. 3760-3765, 2019.

[6] Z. Xu, C. Tighe, M. Galea, T. Hamiti, C. Gerada, and S. J. Pickering, "Thermal design of a permanent magnetic motor for direct drive wheel actuator," Proc. - 2014 Int. Conf. Electr. Mach. ICEM 2014, pp. 2186-2192, 2014, doi: 10.1109/ICELMACH.2014.6960487.

[7] A. Hebala, O. Hebala, W. A. M. Ghoneim, and H. A. Ashour, "Multi-Objective Particle Swarm Optimization of Wind Turbine Directly Connected PMSG," in 2017 Nineteenth International Middle East Power Systems Conference (MEPCON), Cairo, 2017, pp. 1075-1080.

[8] W. A. M. Ghoneim, A. Hebala, and H. Ashour, "A Comparative Study of Winding Configuration Effect on the Performance of Low Speed PMSG Using FEM," in 2016 Eighteenth International Middle East Power Systems Conference (MEPCON), Cairo, 2016, pp. 348-352, doi: 10.1109/MEPCON.2016.7836914.

[9] ZhifuWang, Jingzhe Yang, Huiping Ye, and Wei Zhou, "A review of Permanent Magnet Synchronous Motor fault diagnosis," in 2014 IEEE Conference and Expo Transportation Electrification Asia-Pacific (ITEC Asia-Pacific), 2014, pp. 1-5, doi: 10.1109/ITEC-AP.2014.6940870.

[10] Y. Chen, S. Liang, W. Li, H. Liang, and C. Wang, "Faults and Diagnosis Methods of Permanent Magnet Synchronous Motors : A Review," Appl. Sci., vol. 9, no. 2116, 2019.

[11] S. S. Moosavi, Q. Esmaili, and A. Djerdir, "Inter-turn fault detection in stator winding of PMSM using wavelet transform," in 2017 IEEE Vehicle Power and Propulsion Conference (VPPC), 2017, pp. 4-8. 
[12] K. Ahsanullah, E. Jeyasankar, S. K. Panda, R. Shanmukha, and S. Nadarajan, "Detection and Analysis of Winding and Demagnetization Faults in PMSM based Marine Propulsion Motors," 2017.

[13] Z. Gherabi, N. Benouzza, D. Toumi, and A. Bendiabdellah, "Eccentricity Fault diagnosis in PMSM using Motor Current Signature Analysis," in 2019 International Aegean Conference on Electrical Machines and Power Electronics, 2019, no. 2, pp. 205210.

[14] B. Bessam, A. Menacer, M. Boumehraz, and H. Cherif, "A novel method for induction motors stator inter-turn short circuit fault diagnosis based on wavelet energy and neural network," in 2015 IEEE 10th International Symposium on Diagnostics for Electrical Machines, Power Electronics and Drives (SDEMPED), 2015, pp. 143-149, doi: 10.1109/DEMPED.2015.7303682.

[15] A. Bechkaoui, K. Ouamrane, A. Ameur, and D. Taibi, "Detection of Turn Short Circuit Fault in PMSM Variable Speed based on Adaptive Fuzzy Logic and Sliding-Mode Control A.Bechkaoui1,K.Ouamrane4," in 2015 4th International Conference on Electrical Engineering (ICEE), 2015, pp. 4-9.

[16] J. Yang, M. Dou, Z. Dai, D. Zhao, and Z. Zhang, "Modeling and Fault Diagnosis of Inter-turn Short Circuit for Five-phase PMSM based on Particle Swarm Optimization," in 2016 IEEE Applied Power Electronics Conference and Exposition (APEC), 2016, pp. 3134-3139.

[17] M. Khov, J. Regnier, and J. Faucher, "Monitoring of turn shortcircuit faults in stator of PMSM in closed loop by on-line parameter estimation," 2009 IEEE Int. Symp. Diagnostics Electr. Mach. Power Electron. Drives, SDEMPED 2009, 2009, doi: 10.1109/DEMPED.2009.5292797.

[18] B. Aubert, J. Regnier, S. Caux, and D. Alejo, "Kalman-FilterBased Indicator for Online Interturn Short Circuits Detection in Permanent-Magnet Synchronous Generators," Ind. Electron. IEEE Trans., vol. 62, no. 3, pp. 1921-1930, 2015, doi: 10.1109/TIE.2014.2348934.

[19] W. El Sayed, M. A. El Geliel, and A. Lotfy, "Fault Diagnosis of PMSG Stator Inter-Turn Fault Using Extended Kalman Filter and Unscented Kalman Filter,” Energies, vol. 13, no. 2972, pp. 1-24, 2020, doi: 10.1109/iconc345789.2020.9117536.

[20] Y. Shi, K. Sun, L. Huang, and Y. Li, "Online identification of permanent magnet flux based on extended Kalman filter for IPMSM drive with position sensorless control," IEEE Trans. Ind. Electron., vol. 59, no. 11, pp. 4169-4178, 2012, doi: 10.1109/TIE.2011.2168792.

[21] M. Ruba, C. Oprea, and L. Szabo, "Comparative study on Switched Reluctance Machine based fault-tolerant electrical drive systems," in 2009 IEEE International Electric Machines and Drives Conference, 2009, pp. 987-992.

[22] X. Zhang, C. Xu, and Z. Zhao, "A Novel Fault-Tolerant Topology and Control Method for Open-Winding PMSM System with a Three-Leg Inverter," in 2019 22nd International Conference on Electrical Machines and Systems (ICEMS), 2019, pp. 1-5.

[23] H. Guo, J. Xu, and Y. Chen, "Robust Control of Fault-Tolerant Permanent-Magnet Synchronous Motor for Aerospace Application With Guaranteed Fault Switch Process," IEEE Trans. Ind. Electron., vol. 62, no. 12, pp. 7309-7321, 2015.

[24] S. S. Yeoh, T. Yang, L. Tarisciotti, C. I. Hill, S. Bozhko, and P. Zanchetta, "Permanent-Magnet Machine-Based Starter-Generator System With Modulated Model Predictive Control," IEEE Trans. Transp. Electrif., vol. 3, no. 4, pp. 878-890, 2017, doi: 10.1109/TTE.2017.2731626.

[25] Q. Wang et al., "A Low-Complexity Optimal Switching TimeModulated Model-Predictive Control for PMSM With ThreeLevel NPC Converter," IEEE Trans. Transp. Electrif., vol. 6, no. 3, pp. 1188-1198, 2020

[26] A. A. Abdelrauf, W. W. Saad, A. Hebala, and M. Galea, "Model Predictive Control Based PID Controller for PMSM for Propulsion Systems," in 2018 IEEE International Conference on Electrical Systems for Aircraft, Railway, Ship Propulsion and Road Vehicles \& International Transportation Electrification Conference (ESARS-ITEC), 2018, pp. 1-7, doi: 10.1109/ESARSITEC.2018.8607585.

[27] G. Liu, C. Song, and Q. Chen, "FCS-MPC-Based Fault-Tolerant Control of Five-Phase IPMSM for MTPA Operation," IEEE
Trans. Power Electron., vol. 35, no. 3, pp. 2882-2894, 2020.

[28] A. Kiselev, G. R. Catuogno, A. Kuznietsov, and R. Leidhold, "Finite-Control-Set MPC for Open-Phase Fault-Tolerant Control of PM Synchronous Motor Drives," IEEE Trans. Ind. Electron. vol. 67 , no. 6, pp. 4444-4452, 2020.

[29] Y. Luo and C. Liu, "Pre- and Post-Fault Tolerant Operation of a Six-Phase PMSM Motor Using FCS-MPC Without Controller Reconfiguration," IEEE Trans. Veh. Technol., vol. 68, no. 1, pp. 254-263, 2019.

[30] K. Zawirski, D. Janiszewski, and R. Muszynski, "Unscented and extended Kalman filters study for sensorless control of PM synchronous motors with load torque estimation," Bull. POLISH Acad. Sci. Tech. Sci., vol. 61, no. 4, 2013, doi: 10.2478/bpasts2013-0086.

[31] E. A. Wan and R. Van Der Merwe, "The unscented Kalman filter for nonlinear estimation," in Proceedings of the IEEE 2000 Adaptive Systems for Signal Processing, Communications, and Control Symposium (Cat. No.00EX373), 2002, pp. 153-158, doi: 10.1109/ASSPCC.2000.882463.

[32] A. A. Abdelrauf, M. Abdel-Geliel, and E. Zakzouk, "Adaptive PID controller based on model predictive control," in 2016 European Control Conference (ECC), 2016, pp. 746-751, doi: 10.1109/ECC.2016.7810378.

[33] A. Aboelhassan, M. Abdelgeliel, E. E. Zakzouk, and M. Galea, "Design and Implementation of Model Predictive Control Based PID Controller for Industrial Applications," Energies, vol. 13, no. 24, p. 6594, Dec. 2020, doi: 10.3390/en13246594. 